Advances in Gene Technology: The Genome and Beyond -

Structural Biology for Medicine (Proceedings of the 2002 Miami

Nature Biotechnology Winter Symposium)

TheScientificWorld 2002, 2(S2), 144-145

ISSN 1532-2246; DOI 10.1100/tsw.2002.70

\title{
SOME ASPECTS OF DNA-ETBR INTERACTION PECULIARITIES
}

\author{
Poghos O. Vardevanyan $^{1 *}$, Ara P. Antonyan ${ }^{1}$, Lia A. Minasbekyan ${ }^{1}$, and Armen T. Karapetyan ${ }^{2}$ \\ ${ }^{1}$ Biophysics Department of Yerevan State University, 375025 Yerevan, Armenia; ${ }^{2}$ Physics \\ Department, Yerevan Institute of Architecture and Construction, 375009 Yerevan, Armenia \\ E-mail: ${ }^{*}$ simvar@arminco.com
}

Comparision of theoretical and experimental data of ethidium bromide (EtBr) binding to DNA suggested that this ligand can complex with DNA by several different types of interactions[1,2]. The dependence of temperature transition width from DNA melting curves against the ratio of EtBr/DNA - $r_{b}$ showed inverted bell-shaped profiles $\left(0,25<r_{b}<0,55\right)$.

On increasing the EtBr/DNA ratio, the temperature transition width in DNA melting curves decreased, passed through a minimum, and then slightly increased, indicating that $\mathrm{EtBr}$ binds to both single- and double-stranded DNA (Fig. 1). In addition, the melting curves showed a dependence on ionic strength, indicating that electrostatic interactions influence the different binding modes. Scatchard analysis of fluorescence binding data of EtBr with DNA detected only intercalation of EtBr into DNA (Fig. 2). However, Scatchard analysis of the absorbance binding data detected the intercalative interaction as well as additional binding modes (Fig. 2). Subtraction of the fluorescence titration data from the absorbance data showed that the additional modes of binding involve nonintercalative interactions between $\mathrm{EtBr}$ and both single- and double-stranded DNA (Fig. 2). These results are consistent with previous theoretical and experimental results.

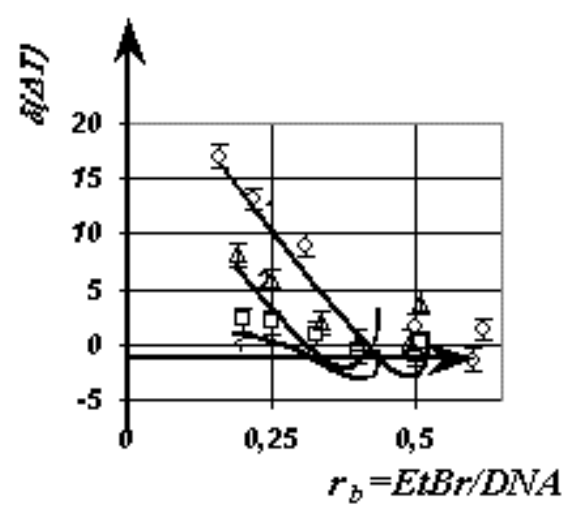

FIGURE 1. Melting curves of complexes of DNA-EtBr at ionic strength $\mu_{\mathrm{Na}+}=2,0 \cdot 10^{-3} \mathrm{M}$ (curve 1 ), $\mu_{\mathrm{Na}^{+}}=1,0 \cdot 10^{-2} \mathrm{M}$ (curve 2), $\mu_{\mathrm{Na}^{+}}=2,0 \cdot 10^{-2} \mathrm{M}$ (curve 3), $\mathrm{pH}=7,0$. The average square deviation errors are shown. 


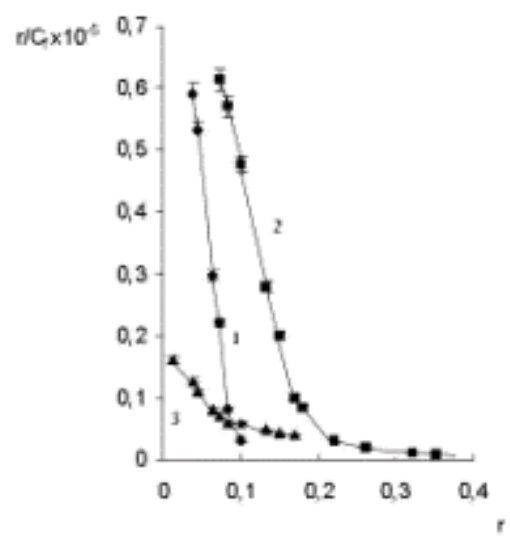

FIGURE 2. The binding curves of EtBr with ds-DNA obtained by Scatchard method from fluorescence (1) and absorbtion (2) spectrum at $\mu_{\mathrm{Na}^{+}}=2 \cdot 10^{-2} \mathrm{M}$. The curve (3) is obtained by subtracting curve (1) from curve (2) and correspond to semi-intercalative complex of EtBr with ds-DNA.

\section{REFERENCES}

1. Karapetian, A.T., Mehraiam, N.M., Terzikian, G.A., Vardevanian, P.O., Antonian, A.P., Borisova, O.F., and Frank-Kamenetskii, M.D. (1996) J. Biomol. Struct. Dynam. 14, 275-283.

2. Vardevanyan, P.O., Antonyan, A.P., Manukyan, G.A., Karapetian, A.T., Shchelkina, A.K., and Borisova, O.F. (2000) Mol. Biol. (Rus) 34(2), 310-315. 

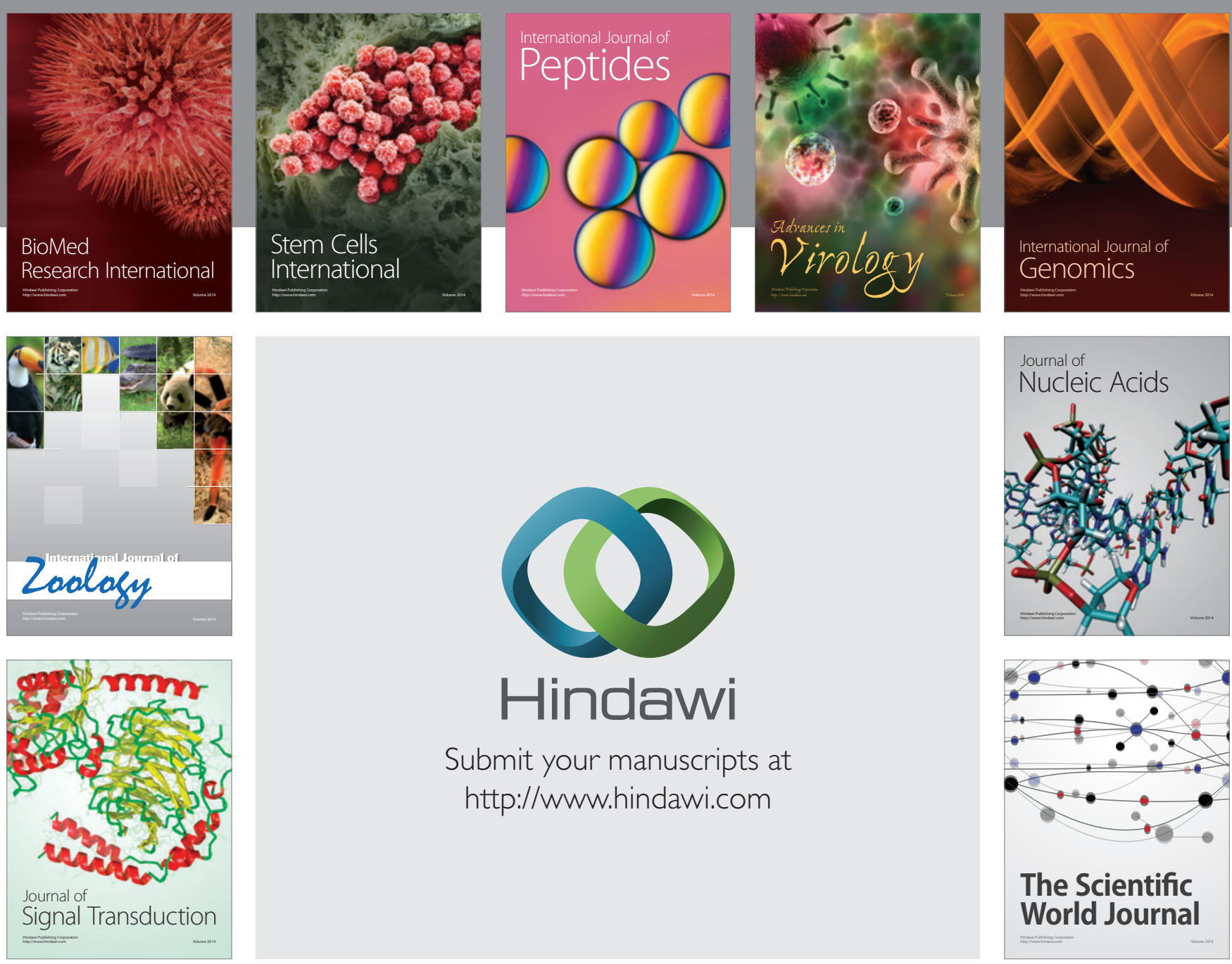

Submit your manuscripts at

http://www.hindawi.com
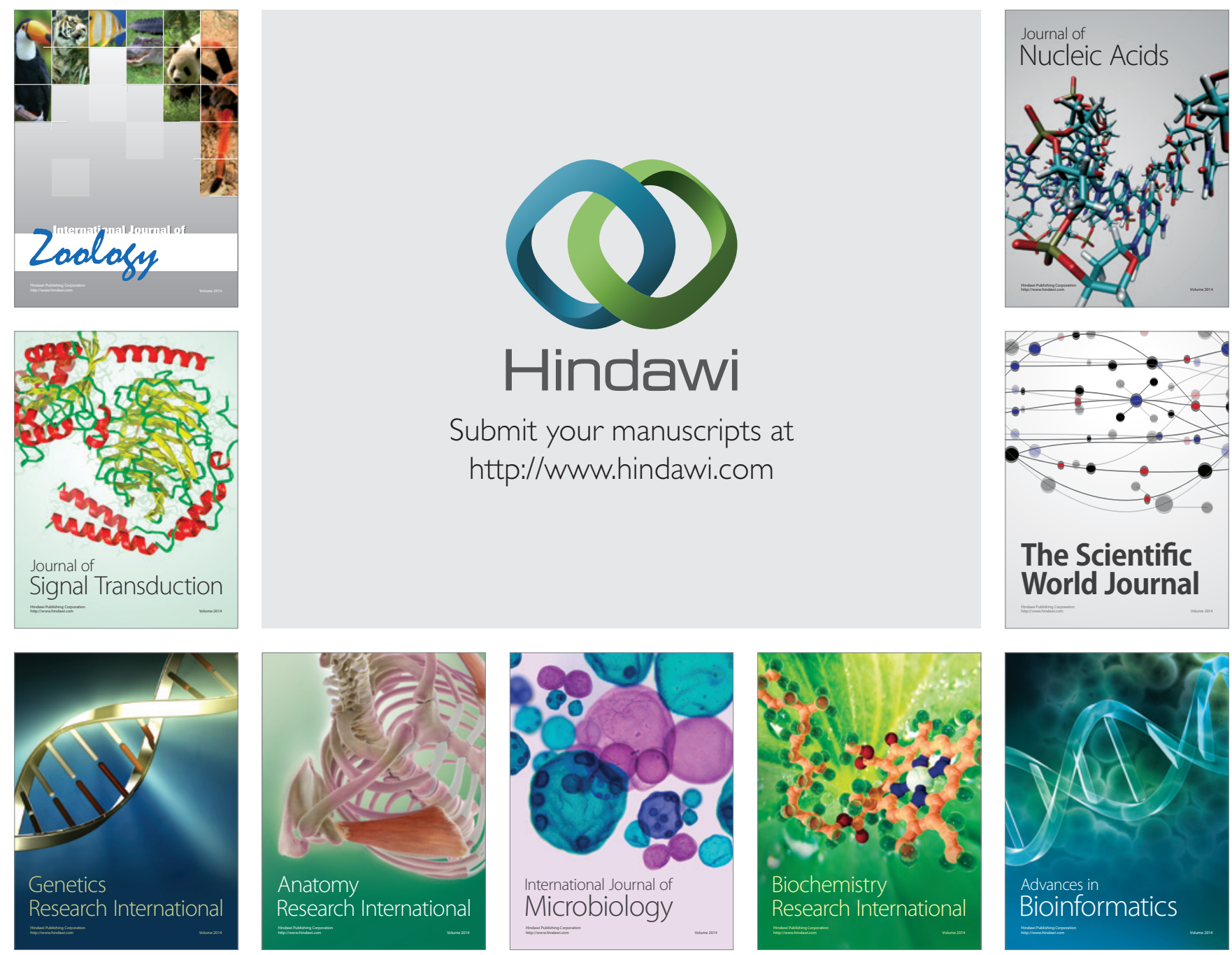

The Scientific World Journal
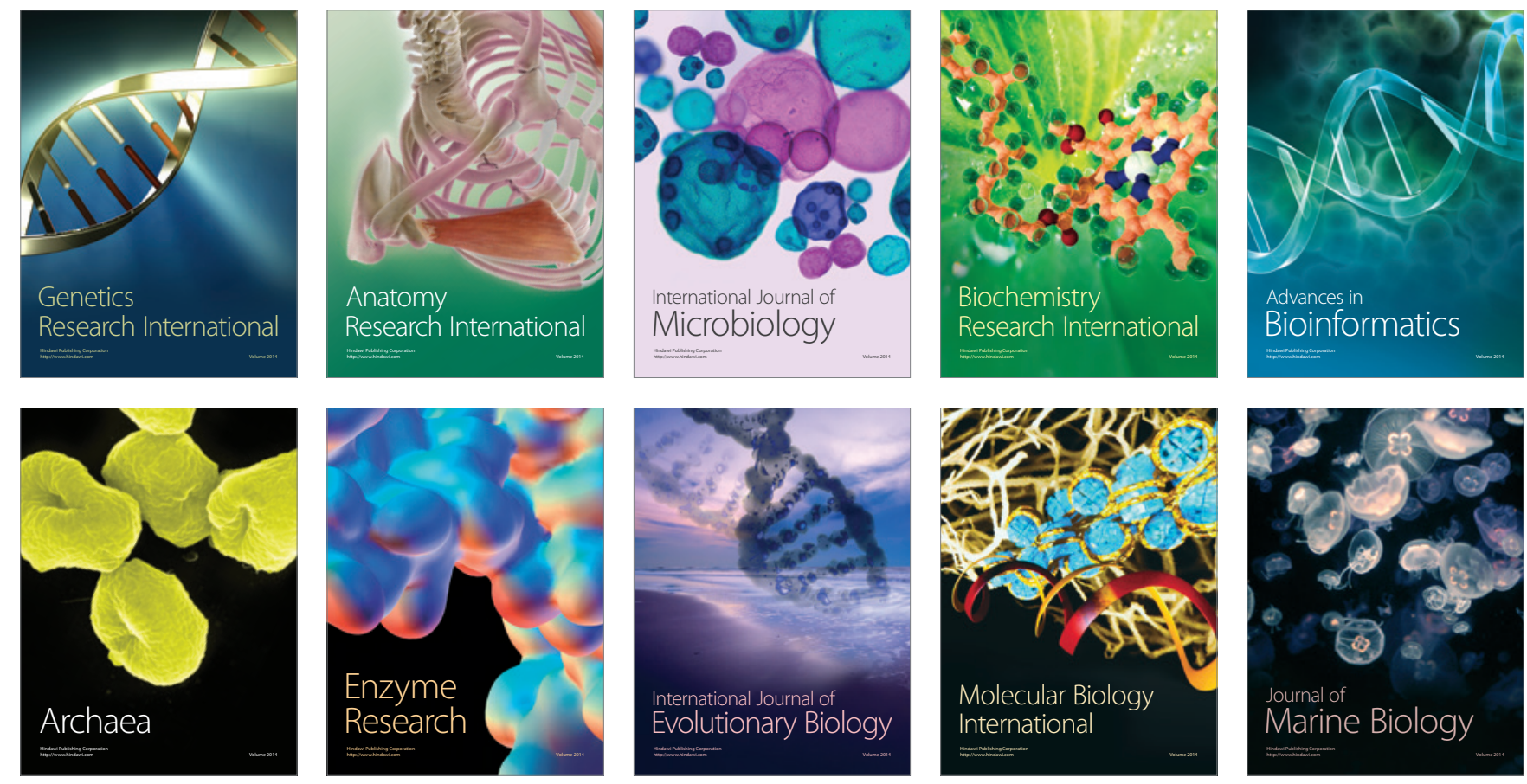